\title{
Laser-associated eye injury: Offering some practical advice
}

\author{
Andrea G. Lantz Powers, MD, MEd, FRCSC
}

Department of Urology, Dalhousie University, Halifax, NS, Canada

Cite as: Lantz Powers AG. Laser-associated eye injury: Offering some practical advice. Can Urol Assoc J 2020;14(12):383-4. http://dx.doi.org/10.5489/cuaj.7043

See related article on page 380

1 read the Canadian Urological Association best practice report (BPR) on Holmium:YAG laser eye safety by Bhojani et al with great interest. The BPR reviews the literature for Ho:YAG laser-associated eye injury and offers practical advice regarding Ho:YAG laser eye protection. Unfortunately, I often doubt that "practical" is included in hospital administration vernacular.

Bhojani et al report that with over 20 years of extensive use, no Ho:YAG laser eye injuries have ever been reported. ${ }^{1}$ In the review of Ho:YAG laser adverse events (AEs) cited in the BPR, there were only 11 AEs related to the medical operator reported from 1992-2012. ${ }^{2}$ Burns, not eye injuries, were the most commonly reported AE. Contrary to this study, however, the authors of the BPR describe a survey of Endourological Society members regarding Ho:YAG laser associated injuries by Paterson et al. ${ }^{3}$ In this report, $19 \%$ of respondents (50 of 264), had witnessed some form of injury related to the laser. This finding would imply that laser-associated AEs may be under-reported, as is common with other AEs in medicine, ${ }^{4}$ but it is reassuring that Paterson's survey found no reports of laser-related eye injury. I have personally witnessed one Ho:YAG-associated burn that a resident suffered when the laser fiber broke and was fired outside the patient. This was a minor, albeit temporarily painful injury that I do not think was reported to any registry. One would hope that serious injuries, such as eye injuries, would be reported, but Paterson's study does cast some doubt on the reliability of the AE reporting system. This may also highlight that we need to improve our reporting of AEs.

The BPR found that a majority of urologists do not routinely wear laser eye protection when using the Ho:YAG laser: $40 \%$ in Paterson et al's study ${ }^{2}$ and $19 \%$ in an international Twitter poll. ${ }^{1}$ These data do come with some limitations; however, if there were a high risk of eye injury with Ho:YAG lasers, one would assume this would be reported in the literature given that most of us do not wear laser eye protection. For those of us who wear prescription glasses (myself included), trying to wear laser goggles over glasses can be an annoying and foggy endeavour. As the BPR outlines, that problem is very common, as it was reported by $70 \%$ of respondents to Paterson et al's survey and is likely a reason why many do not wear the laser eye safety. ${ }^{3}$ I would argue, however, that there is an easy way around this annoyance, which also can provide additional protection outside the scope of this BPR. There is increasing concern regarding the potential for radiation risks to the eye and damage, such as cataracts, ${ }^{5}$ especially for those of us who do high volumes of fluoroscopic procedures (including percutaneous nephrolithotomies). ${ }^{6}$ Fortunately, custom prescription safety glasses can be purchased that can protect against radiation and laser wavelengths. These specialty glasses negate the problems encountered when wearing laser eye protection over prescription glasses. I purchased these specialty glasses when I started practice and they are well worth the cost if you do a large volume of endourological procedures. I have the bonus of staying on side of my hospital's mandatory laser safety eyewear policy, even if the policy may be outdated and not evidence-based. Having my personal eye protection also satisfies my "ick-factor," as I am not wearing something on my face that someone else has worn and may not have been cleaned between uses. Some of my current and former residents sweat... a lot.

One final point I wish to raise is: how will this BPR be used? As a member of my hospital's Laser Committee, I plan to submit this report for discussion, and I hope we can change our policy to align with this BPR. It will be interesting to see if it goes anywhere (again, I will highlight my concern about "practical" not being a frequently used word on many hospital committees). This BPR is at odds with manufacturers' statements about laser safety eyewear, which may make formally changing policy an uphill battle. For example, Lumenis' operator manual for their VersaPulse ${ }^{\circledR}$ PowerSuite $^{\mathrm{TM}}$ laser states that anyone within the nominal ocular hazard distance (NOHD) needs to wear laser safety eyewear. ${ }^{7}$ The NOHD for that laser is $1.1 \mathrm{~m}$, which is a much further distance than the $5 \mathrm{~cm}$ recommended in the BPR. Also, Lumenis specifically warns against using prescription eyewear as a substitute for the recommended laser safety 
eyewear, which is in direct contradiction to the BPR. ${ }^{7}$ The discrepancy between the BPR and the manufacturers' recommendations may be a nail in the coffin for changing the official hospital policy, but perhaps we can continue to turn a blind eye to people who choose not to wear laser safety eyewear and have some evidence to show this is safe.

Competing interests: The author reports no competing personal or financial interests related to this work.

\section{References}

1. Bhojani N, Andonian S, Watterson JD, et al. Canadian Urological Association best practice report: Holmium: YAG laser eye safety. Can Urol Assoc J 2020;14:380-2. hittps://doi.org/10.5489/cuai.6941

2. Althunayan AM, Elkoushy MA, Ehilali MM, et al. Adverse events resulting from lasers used in urology. Endourol 2014;28:256-60. htrps://doi.org/10.1089/end.2013.0451
3. Paterson NR, Fitzpatrick R, Blew B, et al. Perceptions and practice patterns of holmium laser goggles in endourological procedures: An unnecessary evil? J Endourol 2019;33:146-50. https://doi.org/10.1089/end.2018.0432

4. Rodziewicz TL, Houseman B, Hipskind JE. Medical error prevention. [Updated 2020 0ct 17]. In: StatPearls [Internet]. Treasure Island (FL): StatPearls Publishing; 2020 Jan-. Available at: https://www.ncbinlm. nih.gov/books/NBK499956/. Accessed Nov. 3, 2020

5. Shore RE. Radiation and cataract risk: Impact of recent epidemiologic studies on ICRP judgments. Mutat Res 2016;770:231-7. https://doi.org/10.1016/i.mrrev.2016.06.006

6. Hartmann J, Distler F, Baumüller $M$, et al. Risk of radiation-induced cataracts: Investigation of radiation exposure to the eye lens during endourologic procedures. J Endourol 2018;32:897-903. https://doi.org/10.1089/end.2018.0324

7. Lumenis. VersaPulse PowerSuite 20W Holmium Surgical Laser Operator Manual, Sept. 2004. Available at: hitps://www.bioclinicalservices.com.au/sharplan/holmium-surgicallasers/versapulse-powersuite20w-holmium-surgical-laser-operator-manual. Accessed Nov. 3, 2020

Correspondence: Dr. Andrea G. Lantz Powers, Department of Urology, Dalhousie University, Halifax, NS, Canada; andrea.lantz@gmail.com

Search guidelines by specialty, specific topic, and type. Visit the new-and-improved CUA guidelines website and start exploring!

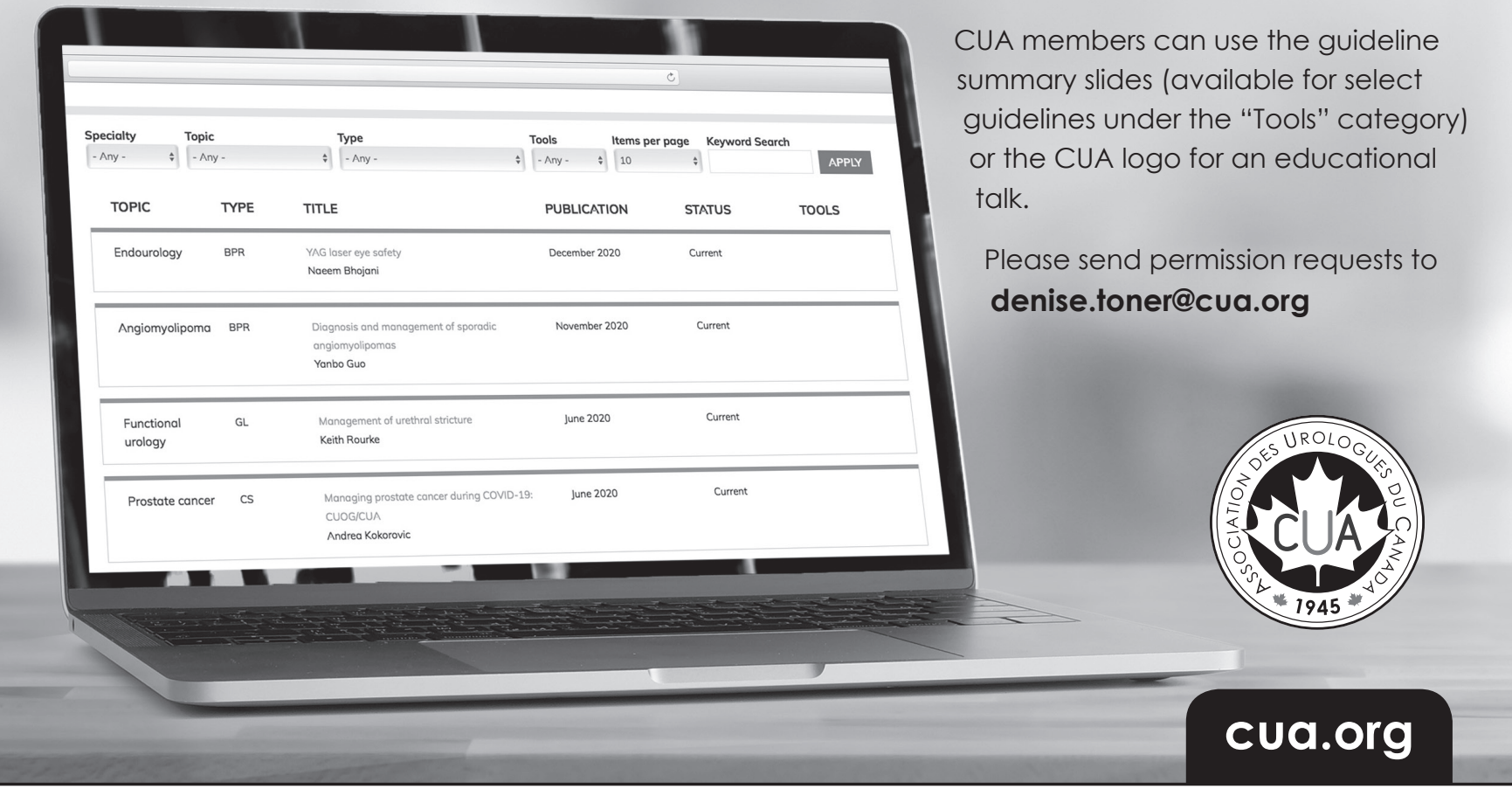

